\title{
Interpreting the Correlation Between Inflation and the Skewness of Relative Prices: A Comment on Bryan and Cecchetti
}

\section{Citation}

Ball, Laurence, and N. Gregory Mankiw. 1999. Interpreting the correlation between inflation and the skewness of relative prices: A comment on Bryan and Cecchetti. Review of Economics and Statistics 81(2): 197-198.

\section{Published Version}

http://dx.doi.org/10.1162/003465399558157

\section{Permanent link}

http://nrs.harvard.edu/urn-3:HUL.InstRepos:3415439

\section{Terms of Use}

This article was downloaded from Harvard University's DASH repository, and is made available under the terms and conditions applicable to Other Posted Material, as set forth at http:// nrs.harvard.edu/urn-3:HUL.InstRepos:dash.current.terms-of-use\#LAA

\section{Share Your Story}

The Harvard community has made this article openly available.

Please share how this access benefits you. Submit a story.

\section{Accessibility}




\title{
INTERPRETING THE CORRELATION BETWEEN INFLATION AND THE SKEWNESS OF RELATIVE PRICES: A COMMENT ON BRYAN AND CECCHETTI
}

\author{
Laurence Ball and N. Gregory Mankiw*
}

\begin{abstract}
A LARGE literature in macroeconomics has examined how the inflation rate is related to the distribution of relative-price changes. This work has established a striking fact: there is a strong correlation between inflation and the skewness of this distribution. When inflation is high, the distribution of relative-price changes is typically skewed to the right; when inflation is low, it is skewed to the left. The oil shocks of the 1970s are one example of this phenomenon: inflation rose while a few goods (oil products) experienced especially large relative-price increases. But the inflationskewness correlation is not just a result of oil-shock years. This fact holds for many time periods and many countries (e.g., Vining \& Elwertowski (1976) and Ball \& Mankiw (1995) for the United States; Amano \& Macklem (1997) for Canada; De Abreu Lourenco and Gruen (1995) for Australia).
\end{abstract}

Bryan and Cecchetti (1999) argue that this fact "need not be a fact at all," because of "small-sample bias." If true, this is an important claim. It would eliminate an apparently robust stylized fact that might otherwise hold a clue to understanding the causes or effects of inflation. We are not, however, convinced by Bryan and Cecchetti's assertion. Our goal in this note is to explain why.

On its face, Bryan and Cecchetti's claim is puzzling. Their paper presents a model in which there is an underlying true distribution of price changes, and the observed distribution is obtained by sampling a subset of these price changes. They show that the skewness of the sample distribution may be correlated with the sample mean even if there is no skewness in the population distribution. This model, however, does not capture the reality of how price indices are constructed. It is not the case that there are a large number of sectors, and the government computes the CPI by sampling a small number of them. Instead, the government measures prices in all sectors (of which there may be a small or large number depending on the level of disaggregation). The observed correlation of the mean and skewness is based on the full population of sectors. So "small-sample bias" does not appear to be possible. Because the data used to construct price indices are comprehensive, one cannot avoid the conclusion that the inflation-skewness correlation is a fact. ${ }^{1}$

Received for publication November 16, 1998. Accepted for publication December 15, 1998.

* Johns Hopkins University, and Harvard University, respectively.

${ }^{1}$ There is a small sample in the sense that there is a limited number of prices measured in each sector: the government does not collect the price of gasoline from every gas pump in the nation. It is unlikely, however, that sampling error from limited data collection has important effects on the measured distribution of relative-price changes. Moreover, this is not the
If the idea of small sample bias is not relevant here, how should one interpret the numerical simulations presented by Bryan and Cecchetti? The substance of their argument, we believe, is that it is easy to explain the correlation between inflation and skewness. Previous authors have worked hard to explain this fact: Ball and Mankiw (1995) propose that this correlation can be explained with "menu cost" models of price adjustment, while Balke and Wynne (1996) argue that it can be explained by a multisector, real-business-cycle model. By contrast, Bryan and Cecchetti generate the inflation-skewness correlation in a much simpler model. Although it would be wrong to interpret their results as showing that the correlation doesn't exist, one could plausibly interpret them as showing that this correlation doesn't prove anything. As they put it, "such statistics are not useful in distinguishing sticky from flexible price-setting behavior in macroeconomic models."

To evaluate this argument, it helps to step back and review the motivation behind the Ball-Mankiw and Balke-Wynne theories. The starting point for these authors is the classical theory of price determination. Central to this theory is the classical dichotomy: relative prices are determined by real factors, and the aggregate price level is determined by monetary factors. Specifically, if there are $N$ sectors in the economy, there are $N$-1 relative prices. Real variables, such as shifts in demand and costs in the various sectors, determine these $N-1$ prices, using any good or combination of goods as the numeraire. The aggregate price level is determined by the supply and demand for money; this idea is summarized by the quantity equation, $M V=P Y$. The $N-1$ relative prices and the price level, which equals the average of all nominal prices, together determine the $N$ nominal prices.

In this classical model, there is no obvious reason that the behavior of the aggregate price level is related to the distribution of relative prices. If $M, V$, and $Y$ remain constant, then $P$ is constant, and any shifts in the distribution of relative prices do not influence the price level. To explain the observed inflation-skewness correlation, one must explain how the economy differs from this classical baseline.

Balke and Wynne offer one story for the inflationskewness correlation. In their model, certain shocks to the economy generate both skewness in the relative-price distribution and changes in aggregate output. For instance, when OPEC raised oil prices, relative prices in energy-related sectors rose by $50 \%$ or more, balanced by smaller relativeprice decreases in the rest of the economy. This generated

small-sample bias that Bryan and Cecchetti are calibrating in their simulations. 
substantial skewness in the distribution. And in Balke and Wynne's real-business-cycle model, the oil price increase also reduces aggregate output. The fact that $Y$ falls implies, by the quantity equation, that $P$ rises if $M$ and $V$ are constant. One can debate whether this effect is large enough to explain the observed inflationary effects of OPEC shocks. But qualitatively, Balke and Wynne have a clear story about how a shock can generate both higher inflation and greater skewness.

Ball and Mankiw take a different approach to explaining the facts: they depart from the assumption of nominal price flexibility implicit in the classical model. As in the classical model, the money supply and the $N-1$ equilibrium relative prices determine the desired nominal prices in the $N$ sectors; holding constant monetary factors, desired changes in nominal prices average to zero. Because of the costs of price adjustment, however, prices adjust only at firms that desire especially large nominal changes. This implies that large changes in desired prices have disproportionately large effects on actual price adjustment. In the case of an oil shock, the large desired adjustments in energy sectors lead these firms to raise their nominal prices. While equilibrium nominal prices fall in all other sectors, they fall by too little in each sector to warrant immediate downward adjustments. Because some nominal prices rise and others do not fall, the overall price level rises.

Bryan and Cecchetti's model includes neither nominal rigidity nor a real-business-cycle relation between relative prices and aggregate output. Instead, they simply assume that nominal prices for different sectors are drawn randomly from a symmetric distribution. Presumably, the realizations of prices in various sectors reflect sectoral shocks. The flaw in the model is the assumption that, if there are $N$ sectors, nominal prices are determined by $N$ draws from the distribution of prices. In this case, if $N$ is small, then one large realization of a nominal price will both raise the average price level and generate skewness. But this model differs from the classical model in assuming that the $N$ independent, sectoral price shocks feed directly into the aggregate price level. Again, in classical theory, the price level is determined by monetary factors, and sectoral shocks determine only the $\mathrm{N}-1$ relative prices. Bryan and Cecchetti do not explain what deviation from this classical benchmark might allow sectoral shocks to affect the price level. Unlike Balke-Wynne and Ball-Mankiw, they offer a statistical "explanation" for the observed inflation-skewness correlation without any obvious economic interpretation.

One can build intuition for these issues by again considering the OPEC price increases of the 1970s. At the time, it appeared obvious to many laymen that higher oil prices meant higher inflation, simply because oil prices are an important component of price indices. By contrast, Milton Friedman argued in 1975 that this shock was not inflationary. According to Friedman, the layman's view was based on the flawed idea that sectoral shocks determine nominal prices, and that the aggregate price level is determined by the sum of these prices. Friedman pointed out that the OPEC shock was a rise in a certain relative price, and that, whenever one relative price rises, there must by definition be other relative prices that are falling. Shifts in the $N$-1 relative prices are consistent with any level for aggregate $P$, and so monetary factors are needed to pin down $P$. Friedman asks, "Why should the average level of all prices be affected significantly by changes in the prices of some things relative to others?" and suggests that there is no good answer. History has shown that Friedman was wrong in practice: the OPEC shocks did cause inflation. But he is right in theory, if one assumes the basic classical model. Thus, the challenge for macroeconomists is to find the deviations from this classical benchmark that explain the facts. Instead of doing this, Bryan and Cecchetti merely offer a statistical version of the layman's misconception.

\section{REFERENCES}

Amano, Robert A., and R. Tiff Macklem, "Menu Costs, Relative Prices, and Inflation: Evidence for Canada," Bank of Canada Working Paper 97-14 (June 1997).

Balke, Nathan S., and Mark A. Wynne, "An Equilibrium Analysis of Relative Price Changes and Aggregate Inflation," Research Department Working Paper 96-09, Federal Reserve Bank of Dallas (1996).

Ball, Laurence, and N. Gregory Mankiw, "Relative-Price Changes as Aggregate Supply Shocks," Quarterly Journal of Economics 110 (February 1995), 161-193.

Bryan, Michael F., and Stephen G. Cecchetti, "Inflation and the Distribution of Price Changes," this Review 81(2), 188-196.

De Abreu Lourenco, Richard, and David Gruen, "Price Stickiness and Inflation," Research Discussion Paper \#9502, Reserve Bank of Australia (March 1995).

Friedman, Milton, "Perspectives on Inflation," Newsweek (June 24, 1975), 73.

Vining, Daniel R., Jr., and Thomas C. Elwertowski, "The Relationship Between Relative Prices and the General Price Level," American Economic Review 66 (September 1976), 699-708. 
This article has been cited by:

1. DAVID DEMERY, NIGEL W. DUCK. 2008. Relative Prices as Aggregate Supply Shocks with Trend Inflation. Journal of Money, Credit and Banking 40:2-3, 389-408. [CrossRef] 